\title{
Empleo público
}

\author{
Alfonso Esteban MigueL* \\ Doctor en Derecho \\ Universidad Autónoma de Madrid
}

Palabras clave: empleo público local; negociación colectiva en el sector público; contratación temporal en las Administraciones públicas; interinos.

Keywords: local public employment; collective bargaining in the public sector; tempory hiring in public administrations; interim workers.

SUMARIO: I. INTRODUCCIÓN.-II. EL AÑO DE LA PANDEMIA DE COVID-19: INCIDENCIA EN EL EMPLEO PÚBLICO: 1. Efectos del estado de alarma en el empleo público. 2. La regulación del teletrabajo como consecuencia de la covid-19.--III. TEMPORALIDAD EN LA ADMINISTRACIÓN: 1. Novedades jurisprudenciales en torno a la contratación laboral temporal en la Administración: 1.1. La contratación eventual en la Administración: ‘es posible su utilización para cubrir vacaciones de la plantilla? 1.2. El abuso en la contratación temporal en la Administración y la teoría de «la unidad esencial del vínculo». 1.3. Los abusos en la contratación temporal de las sociedades públicas se sanciona con la conversión en indefinido no fijo. 1.4. Reconocimiento judicial de derechos para el personal laboral temporal e indefinido no fijo. 2. Novedades jurisprudenciales en torno a la figura del funcionario interino: 2.1. El cese de los funcionarios internos. 2.2. El abuso en el nombramiento sucesivo de interinos ante el Tribunal de Justicia de la Unión Europea. 2.3. Reconocimiento judicial de condiciones de trabajo al personal interino.-IV. EL CONVENIO COLECTIVO COMO FUENTE REGULADORA DE LAS CONDICIONES DE TRABAJO DEL PERSONAL DE UN AYUNTAMIENTO: 1. Convenio colectivo aplicable cuando el ayuntamiento carece de convenio colectivo propio. 2. Convenio colectivo aplicable cuando el ayuntamiento contrata mediante programas de subvenciones.

\section{INTRODUCCIÓN}

El año 2020 será recordado por todos por la pandemia de covid-19. Una crisis sanitaria sin precedentes que ha obligado a paralizar la actividad normal de todos los

* Con la colaboración de María de Sande Pérez-Bedmar, profesora de Derecho del Trabajo y de la Seguridad Social UAM (en excedencia). 
países del mundo para luchar contra el avance de un coronavirus muy contagioso y con elevada tasa de mortalidad. En España, por primera vez en su historia reciente, se decretó mediante un estado de alarma un confinamiento domiciliario estricto que únicamente permitió que los ciudadanos salieran a la calle para realizar las actividades más esenciales bajo importantísimas limitaciones. Universidades, colegios, escuelas infantiles, centros de día de mayores, comercios, fábricas, gimnasios, locales de restauración y un gran etcétera de empresas e instalaciones no esenciales tuvieron que cerrar sus puertas y paralizar su actividad de forma presencial. Semanas muy duras que obligaron a tomar medidas legislativas extraordinarias y decisiones ejecutivas con un fin: evitar la saturación hospitalaria, reducir los niveles de contagio y salvar el mayor número de vidas posible.

Esta situación excepcional ha influido, como no podía ser de otra manera, en el empleo público. Empleados públicos que han luchado en primera línea contra el virus, que han puesto de relieve su compromiso con la ciudadanía y su vocación de servicio público. En especial, el personal sanitario que han sido los héroes anónimos en esta batalla, pero también los cuerpos y fuerzas de seguridad y otros muchos empleados que bien presencialmente, bien desde sus casas, se han esforzado al máximo para salir cuanto antes de esta situación y cubrir las necesidades de todo el país. Una labor encomiable que nos deja en deuda con ellos como sociedad. Muestra de ello eran los aplausos que desde ventanas y balcones se daban con una emoción y gratitud indescriptibles cada día a las ocho de la tarde.

Como en informes anteriores, es el momento de dar cuenta de las novedades del 2020 en materia de empleo público. Teniendo en cuenta que la crisis sanitaria ha condicionado sobremanera la regulación y las medidas sobre el empleo público en el último año, la primera parte de este informe se dedicará a analizar estas cuestiones, aunque será necesario que pase más tiempo para hacer un estudio en profundidad sobre temas tan relevantes como, por ejemplo, la regulación del trabajo a distancia o teletrabajo.

Pero la actividad judicial también ha continuado durante el 2020, con la adaptación obligada por la situación sanitaria. En este último año se han producido importantes pronunciamientos judiciales tanto en el orden social como en el contencioso-administrativo en materia de empleo público. Cuenta de ello se da en los siguientes apartados de este informe. No nos hemos centrado en exclusiva en sentencias sobre empleo público local, sino que también se analizarán sentencias de otras Administraciones, que por su importancia tienen una repercusión o incidencia directa en la regulación del empleo público local.

\section{EL AÑO DE LA PANDEMIA DE COVID-19: INCIDENCIA EN EL EMPLEO PÚBLICO}

\section{Efectos del estado de alarma en el empleo público}

El 14 de marzo de 2020 será una fecha que toda una generación de españoles no olvidará. Ese día se publicó en el Boletín Oficial del Estado el Real Decreto 463/2020, de 
14 de marzo, por el que se declara el estado de alarma para la gestión de la situación de crisis sanitaria ocasionada por el covid-19 (BOE núm. 67). Aunque la situación sanitaria llevaba semanas empeorando por la expansión de la covid-19 y se fueron tomando medidas para su contención desde el Estado, las Comunidades Autónomas y los entes locales, el estado de alarma supuso un punto de inflexión. Con una duración inicial de quince días, que luego se extendió hasta el 21 de junio de 2020, se decretó la limitación de la libertad de circulación de las personas con excepciones, entre ellas, el desplazamiento al lugar de trabajo. Sin embargo, se suspendieron las actividades presenciales educativas de todos los niveles y se cerraron al público todos los locales, establecimientos e instalaciones que no desarrollaran una actividad esencial. Ello provocó que muchos trabajos se tuvieran que desarrollar en modalidad no presencial, aunque sin una regulación detallada. El empleo público no fue ajeno a esta situación, también tuvo que adaptar todos los puestos de trabajo que no fueran esenciales y que no se tuvieran que prestar de forma presencial para realizarlos a distancia. Y también hubo que buscar soluciones para aquellos trabajadores que no podían prestar sus servicios a distancia pero tampoco de forma presencial.

En este contexto, la legislación laboral y las instituciones del Derecho del Trabajo se pusieron a prueba en circunstancias tan excepcionales como la paralización de casi toda la actividad del país. Se buscaron mecanismos en la legislación laboral para evitar los despidos que pudieran haberse producido por el cierre temporal de muchos comercios e industrias. Las suspensiones de los contratos de trabajo mediante los expedientes de regulación temporal de empleo (ERTE), regulados en el art. 47 del Estatuto de los Trabajadores (en adelante ET), han sido el mecanismo que ha permitido mantener esos puestos de trabajo. Sin embargo, la situación extraordinaria se está prolongando mucho en el tiempo y habrá que esperar para evaluar la eficacia de este instrumento jurídico.

No obstante, las Administraciones públicas no han podido hacer uso de este instrumento con el personal laboral que no pudo prestar sus servicios en forma de teletrabajo ni tampoco presencialmente porque su actividad quedó suspendida. Ello porque en la reforma laboral de 2012 se introdujo una disposición adicional en el Estatuto de los Trabajadores que expresamente prohíbe la aplicación de estas medidas a las Administraciones y a las entidades de Derecho público vinculadas o dependientes de ellas. Sobre esta cuestión se publicaron dos entradas en el blog del IDL-UAM: A. EsTEBAN MigueL, ERTES en el sector público (I): la necesidad de replantearse la probibición y ERTES en el sector público (II): situación de las entidades del sector público empresarial (www.idluam.org/blog/).

Todas las medidas extraordinarias que se pusieron en marcha con el estado de alarma no surtieron el efecto deseado o no con la intensidad pretendida. Es por ello que se fueron buscando otras medidas que permitieran bajar la presión hospitalaria y el número ascendente diario de fallecidos por la covid-19. Se demostró que la limitación de la movilidad de la población era una de las mejores barreras para la propagación del virus y por ello se aprobó el Real Decreto-ley 10/2020, de 29 de marzo, por el que se regula un permiso retribuido recuperable para las personas trabajadoras por cuenta ajena que no presten servicios esenciales, con el fin de reducir la movilidad de la población en el contexto de 
la lucha contra el covid-19 (BOE núm. 87). Esta medida generó muchas dudas jurídicas relacionadas con el límite subjetivo del permiso aprobado por el real decreto-ley. En concreto, si era aplicable a los empleados públicos que estuvieran en la situación descrita en su articulado. Fueron numerosas las entradas públicas comentando esta normativa y su posible aplicación a las Administraciones públicas. Entre ellas: I. BELTRÁn DE HEREDIA, Covid-19 y RDLey 107/2020: comentario de urgencia sobre el permiso retribuido recuperable (www.ignasibeltran.com), y L. GORDO GONZÁLEZ, RDL 10/2020: ¡se aplica el permiso retribuido recuperable obligatorio a los empleados públicos? (www.idluam.org/blog/). También, D. GUTIÉRREZ COLOMINAS, «La naturaleza y caracterización del permiso retribuido, recuperable y obligatorio previsto en el Real Decreto Legislativo 10/2020", Revista de Derecho Social, 91/2020, pp. 69-94.

Las consecuencias de la pandemia en el empleo público y en el empleo en general se están viendo y se verán a largo plazo. Será necesario volver a la normalidad para evaluar con sosiego si la legislación en esta materia estaba preparada para una situación tan excepcional y si las reformas que se han ido realizando como una verdadera regulación de emergencia han servido para los propósitos buscados. Han sido numerosas las jornadas, conferencias o coloquios que se han ido desarrollando durante todo el 2020 para ir apuntando algunas pinceladas sobre estas cuestiones. El 4 y 7 de mayo de 2020 se desarrolló el seminario web del IDL-UAM: «Entidades locales y covid-19: estado de alarma y lo que viene después», donde entre otras ponencias relacionadas con el ámbito local no podía faltar una sobre cómo estaba afectando la pandemia al empleo público local y las perspectivas de futuro: A. EsTEBAN Miguel, «El empleo público local en la crisis del covid-19", que puede verse en www.idluam.org/blog/seminarios/.

\section{La regulación del teletrabajo como consecuencia de la covid-19}

En España se habían dado tímidos avances en formas de trabajo a distancia, especialmente en la empresa privada. La estructura de la Administración no había permitido hasta el momento un cambio en la forma de trabajar que permitía la revolución de las tecnologías. Alguna Administración de manera aislada había comenzado a dar pasos en este sentido, pero con un horizonte a medio o largo plazo. Pero todo esto cambió con la pandemia provocada por la covid-19. Como se ha mencionado anteriormente, las medidas impuestas para limitar la circulación de personas con el objetivo de frenar la expansión del virus obligaron a que una gran parte de los empleados públicos y de los trabajadores en general tuvieran que prestar sus servicios a distancia sin acudir de manera presencial a su puesto de trabajo. Se evidenció muy pronto que era necesaria una mayor regulación de un fenómeno que se produjo de manera brusca, pero a la vez se ha convertido en una forma de trabajar que se irá consolidando incluso cuando se recupere la normalidad.

El interés por el teletrabajo se ha intensificado en el último año, unido a la pandemia y a la nueva regulación. Cuenta se ello se dio en las jornadas celebradas el 13 de octubre en el IDL-UAM bajo el título «Teletrabajo en la administración» y que puede verse en 
www.idluam.org/blog/seminarios/. En ellas se debatió sobre la regulación y las consecuencias del teletrabajo en los entes locales con responsables de la Administración, representantes sindicales y especialistas en la materia. También se dedicó una ponencia sobre teletrabajo y empleo público por E. M. SIERRA BENíTEZ en el Congreso sobre Regulación del Teletrabajo organizado por la Universitat de València en octubre y noviembre de 2020. En diciembre de ese año también se publicó una obra colectiva sobre esta materia y en la que se dedica el Capítulo VII al teletrabajo en las Administraciones públicas: VVAA, T. SAla Franco (dir.), El teletrabajo, Tirant lo Blanch, Valencia, 2020.

La regulación específica del teletrabajo como forma de trabajo se ha producido en septiembre de 2020 con el Real Decreto-ley 29/2020, de 29 de septiembre, de medidas urgentes en materia de teletrabajo en las Administraciones públicas y de recursos humanos en el Sistema Nacional de Salud para hacer frente a la crisis sanitaria ocasionada por la covid-19 (BOE núm. 259 de 30 de septiembre), que introduce un nuevo art. 47 bis al Estatuto Básico del Empleado Público (en adelante EBEP). Dentro del Capítulo V, «Derecho a la jornada de trabajo, permisos y vacaciones» y seguido del art. 47 que regula la jornada de los funcionarios públicos, se regula el teletrabajo. Se define el teletrabajo como «aquella modalidad de prestación de servicios a distancia en la que el contenido competencial del puesto de trabajo puede desarrollarse, siempre que las necesidades del servicio lo permitan, fuera de las dependencias de la Administración, mediante el uso de tecnologías de la información y comunicación». Para esta modalidad de trabajo se requiere autorización expresa y tendrá carácter voluntario y reversible. Además, se establece que la Administración tendrá que proporcionar y mantener los medios tecnológicos necesarios para la actividad. Como se puede apreciar, es una regulación de mínimos que deja margen a la aprobación de normas de desarrollo, que deberán ser objeto de negociación colectiva.

Es necesario apuntar que en el apartado 5 del art. 47 bis se establece que «el personal laboral al servicio de las Administraciones públicas se regirá, en materia de teletrabajo, por lo previsto en el presente Estatuto y por sus normas de desarrollo». Con esta previsión se evitan posibles confusiones por la diferente naturaleza jurídica del empleado público y la dualidad de regímenes jurídicos. En cambio, todo el personal que preste servicios en entidades públicas o privadas que pertenezcan al sector público pero que no tengan la consideración de Administraciones públicas se regirá por la regulación recogida en el Estatuto de los Trabajadores.

\section{TEMPORALIDAD EN LA ADMINISTRACIÓN}

La contratación temporal en la Administración ha sido objeto de numerosas controversias en los últimos años. Las limitaciones presupuestarias, especialmente la reducida o incluso nula tasa de reposición de efectivos, han provocado que se acuda a la contratación temporal para cubrir necesidades de personal para la actividad habitual y normal de la Administración. Han sido numerosas las resoluciones judiciales enjuiciando cuestiones relativas a la contratación temporal irregular y no en pocas ocasiones con resultado 
distinto. Esta cuestión no ha sido tratada exclusivamente por los tribunales nacionales, sino que el Tribunal de Justicia de la Unión Europea ha dictado varias sentencias sobre la materia. Cuenta de ellas se da en E. Rojo TORRECILla, Extinción de la relación de trabajo en el empleo público interino. El impacto de la jurisprudencia del TJUE (2016-2020), CEMICAL, Barcelona, 2020.

En los últimos años las leyes presupuestarias han permitido llevar a cabo procesos de estabilización del personal. De esta forma, las plazas que han estado ocupadas de forma temporal e interrumpida durante el periodo marcado por la ley pueden ser cubiertas por personal fijo mediante los procedimientos reglamentarios. Con esta medida se ha intentado paliar el problema de la elevadísima tasa de temporalidad en el sector público. Sin embargo, no ha sido suficiente y es necesario buscar nuevos instrumentos que permitan reducir dicha tasa. Sobre esta cuestión es interesante ver el análisis realizado por R. RoQUETA BUJ, «Los procesos de estabilización del empleo temporal en la Administración», Revista V-Lex, núm. 1, 2020, pp. 9-45.

\section{Novedades jurisprudenciales en torno a la contratación laboral temporal en la Administración}

\subsection{La contratación eventual en la Administración: ¿es posible su utilización para cubrir vacaciones de la plantilla?}

Los contratos eventuales han generado muchas dudas sobre su aplicación en las Administraciones públicas. Cuándo se podía utilizar este tipo de contratos o los requisitos necesarios para su justificación han sido algunas de las cuestiones que se han generado en torno a este tipo de contratación temporal. En la Sentencia de la Sala de lo Social del Tribunal Supremo de 10 de noviembre de 2020 (rec. núm. 2323/2018) (ECLI:ES:TS:2020:3833) se plantean dos cuestiones importantes relacionadas con la contratación eventual en un organismo provincial de la Diputación de Sevilla. Por un lado, si es válido un contrato eventual donde se refleja como causa de temporalidad de forma genérica «la realización de las tareas propias de la oficina». Por otro, si puede entenderse como causalidad justificativa de un contrato eventual cubrir el déficit de trabajadores derivado de los descansos, vacaciones y permisos de los que disfruta el personal de plantilla.

Con relación a la primera cuestión, la Sala recuerda que el art. 15.1.b) ET establece los requisitos formales propios de la modalidad contractual temporal. Entre ellos se exige que se exprese con precisión y claridad la causa o circunstancias que justifiquen la contratación. No obstante, la falta de concreción no impide que se analice la efectiva realidad de la causa, al admitirse prueba en contrario que demuestre que el contrato obedecía a la concurrencia de la misma, pese a su defectuosa plasmación formal.

Para dar respuesta a la segunda cuestión sobre la justificación de un contrato eventual para cubrir las vacaciones de la plantilla, el Tribunal Supremo determina en 
base a sus pronunciamientos anteriores que es admisible que, en el caso de las Administraciones públicas, la insuficiencia coyuntural de plantilla para atender el servicio público puede constituir una causa de eventualidad que justifique la utilización de un contrato temporal por acumulación de tareas. Especialmente, cuando los procesos de creación y cobertura de plaza tienen que seguir un procedimiento reglado que se puede extender en el tiempo y no es posible dar una respuesta rápida con la contratación indefinida.

Ahora bien, la utilización del contrato eventual exige la concurrencia real de dicha causa, no pudiendo servir al respecto la mera mención a las vacaciones de otros trabajadores. Ello porque la ausencia por vacaciones de los trabajadores de la plantilla es una circunstancia plenamente previsible y conocida por el organismo público o la Administración, que debe dar respuesta con la plantilla fija al volumen de actividad habitual. Por consiguiente, no es ajustada a Derecho la cobertura temporal de funciones de personal que está disfrutando de vacaciones o permisos mediante contratos de interinidad por sustitución ni por contratos eventuales, ya que no se produce la excepcionalidad que debe acreditarse para la celebración de este tipo de contratos.

\subsection{El abuso en la contratación temporal en la Administración y la teoría de "la unidad esencial del vínculo»}

Son numerosos los pronunciamientos que se han producido durante el año 2020 relacionados con la contratación temporal abusiva por parte de las Administraciones públicas o sus entes dependientes. Una de las cuestiones más controvertidas relacionadas con la contratación temporal es si una subvención específica que permite la financiación de contratos laborales justifica la celebración de un contrato por obra o servicio determinado.

El Pleno de la Sala de lo Social del Tribunal Supremo en su Sentencia de 9 de diciembre de 2020 (rec. núm. 3954/2018) (ECLI:ES:TS:2020:4285) resuelve un recurso de casación para la unificación de doctrina interpuesto por una trabajadora de la Diputación Provincial de Huelva que alega la existencia de fraude en la contratación por la sucesión de varios contratos temporales. También plantea que debe aplicarse la doctrina jurisprudencial relativa a la «unidad esencial del vínculo» para el cálculo de la indemnización por despido.

La actora prestó servicios a favor de la Diputación Provincial de Huelva como oficial administrativa mediante un total de veinte contratos temporales desde junio de 2000 hasta julio de 2015. Los dos primeros fueron contratos eventuales por acumulación de tareas y los restantes por obra o servicio determinado. La sentencia del Juzgado de lo Social, confirmada por el Tribunal Superior de Justicia de Andalucía, desestimó la demanda por despido al entender que la Diputación Provincial de Huelva actuó conforme a Derecho porque los contratos estaban vinculados a subvenciones del Servicio Andaluz de Empleo. 
El Pleno en la sentencia analizada se pronuncia sobre dos cuestiones interesantes. La primera si en el caso concreto existe fraude de ley en la contratación temporal, pese a que los contratos temporales estaban vinculados a subvenciones. Y la segunda si es aplicable la teoría de la «unidad esencial del vínculo» para el cálculo de la indemnización por despido.

En relación con la primera cuestión, sobre si la existencia de una subvención justifica la contratación temporal, la Sala recuerda su doctrina y determina que la existencia de una subvención no es un elemento decisivo y concluyente para la validez de un contrato temporal causal. La licitud de la contratación temporal no puede depender exclusivamente de la existencia de una subvención, siendo obvio que también pueden financiarse servicios permanentes en los entes públicos por medio de subvenciones. Para justificar la modalidad contractual de obra o servicio determinado, el contrato debe reunir consistencia, individualidad y sustantividad propia, siendo necesario que el objeto sea intrínsecamente temporal y se encuentre suficientemente identificado. No puede utilizarse la contratación temporal para desempeñar durante amplios periodos una actividad habitual y ordinaria de la empresa.

En el caso concreto, según el Tribunal Supremo, la trabajadora había desarrollado «una actividad habitual y normal — no coyuntural, ni puntual— de la Diputación Provincial de Huelva»; por tanto, «la autonomía del contrato temporal se desdibujó, convirtiéndose en una actividad reiterada en múltiples ocasiones». En consecuencia, se estima el primer motivo de casación y se declara la existencia de fraude de ley en la contratación temporal de la demandante. Anteriormente, el Tribunal Supremo ya había declarado en las Sentencias de la Sala de lo Social de 4 de marzo de 2020 (rec. núm. 2165/2017) (ECLI:ES:TS:2020:853) y en la de 8 de septiembre de 2020 (rec. núm. 4192/2017) (ECLI:ES:TS:2020:4443) que los contratos por obra o servicio determinado celebrados por una Agencia de Andalucía y financiados en el marco de un programa del Fondo Social Europeo y por el Instituto Andaluz de la Mujer tenían carácter fraudulento por tratarse de actividades propias de la Agencia demandada y carecer de autonomía y sustantividad propia. Además, la existencia de subvención específica no justificaba la temporalidad.

Respecto a la aplicación de la «unidad esencial del vínculo» para realizar el cálculo de la indemnización por despido, computando la antigüedad de la demandante desde la primera de las contrataciones, el Tribunal recuerda que esta doctrina es distinta en función de si opera a efectos del complemento por antigüedad o de la indemnización extintiva.

Con relación al complemento de antigüedad, la Sala sostiene que al tratarse de un plus que compensa la adscripción de un trabajador a la empresa o la experiencia adquirida durante el tiempo de servicio, ambas circunstancias no se modifican por el hecho de existir interrupciones más o menos largas en el servicio al mismo empleador, máxime cuando tales interrupciones son imposición de este.

A efectos del cálculo de la indemnización extintiva se afirma con carácter general que en la sucesión de contratos temporales se computa la totalidad del tiempo de prestación 
de servicios a efectos de antigüedad, cuando ha existido la unidad esencial del vínculo, lo que comporta que no se consideren con carácter general las interrupciones de menos de veinte días, pero también superiores, cuando la misma no sea significativa a efectos de romper la continuidad de la relación laboral existente, dependiendo de las circunstancias del caso.

Cuando se aprecia fraude en la contratación temporal, debe imponerse, si cabe, «un criterio más relajado — con mayor amplitud temporal — en la valoración del plazo que deba entenderse «significativo» como rupturista de la unidad contractual, habida cuenta de que la posición contraria facilitaría precisamente el éxito de la conducta defraudadora». Esta doctrina se ajusta a lo establecido por el Tribunal de Justicia de la Unión Europea al interpretar la Directiva 99/70/CE en el sentido de que «se opone a una normativa nacional que considera que únicamente deben calificarse de sucesivos los contratos o relaciones laborales de duración determinada que no estén separados entre sí por un intervalo superior a veinte días laborales».

Por todo lo expuesto, el Tribunal sostiene que en el supuesto enjuiciado es necesario computar todo el periodo trabajado por la demandante ya que «se trata de una prolongación en el tiempo de una situación ilegal que minora la relevancia de las interrupciones contractuales producidas entre la finalización de cada contrato temporal y la suscripción del siguiente», aunque la interrupción mayor sea de más de cuatro meses.

También han sido numerosos los pronunciamientos del Tribunal Supremo sobre la interpretación del art. 70.1 del Estatuto Básico del Empleado Público, donde se establece que las ofertas de empleo públicas tienen que desarrollarse dentro del plazo improrrogable de tres años en relación con la declaración de irregularidades en la contratación del personal temporal cuando se ha sobrepasado este plazo. En relación con ello, la Sala 4. ${ }^{a}$ ha manifestado que el plazo de tres años no puede operar de modo automático para declarar la contratación temporal como irregular, habrá que estar a las circunstancias específicas de cada supuesto. También es posible que el contrato temporal se haya desnaturalizado antes del paso de tres años porque haya existido fraude o abuso en la contratación. Sirvan como ejemplo las Sentencias de la Sala de lo Social de 9 de diciembre de 2020 (rec. num. 2349/2018) (ECLI:ES:TS:2020:4239) y la de 6 de febrero de 2020 (rec. núm. 2726/2018) (ECLI:ES:TS:2020:517), así como las de 10 de junio y de 16 de julio de 2020 (recs. núms. 4827/2018 y 4724/2018, respectivamente) (ECLI:ES:TS:2020:2784 y ECLI:ES:TS:2020:2749).

\subsection{Los abusos en la contratación temporal de las sociedades públicas se sancionan con la conversión en indefinido no fijo}

La aplicación de la doctrina de los indefinidos no fijos ha sido pacífica en las resoluciones judiciales que se han pronunciado sobre irregularidades en la contratación temporal de la Administración. Sin embargo, no ha sido así en el reconocimiento de esta figura en las sociedades mercantiles públicas. Basta con hacer un recorrido por los 
distintos pronunciamientos de la Sala $4 .{ }^{\mathrm{a}}$ del Tribunal Supremo sobre esta materia para ver los vaivenes que ha sufrido esta cuestión en los últimos años.

Inicialmente, la doctrina judicial aplicó la condición de indefinido no fijo a trabajadores de las sociedades mercantiles públicas (entre otras, SSTS Sala de lo Social de 22 de febrero de 2007 o de 6 de octubre de 2008, recs. núms. 3353/2005 y 3064/2007, respectivamente). En estos supuestos, el Tribunal Supremo concluyó que como sociedades mercantiles públicas pertenecían al sector público y en la selección de su personal se aplicaban los mismos principios que a la Administración, por lo que la contratación irregular de su personal no conducía a la adquisición de fijeza, sino que su relación laboral era de indefinidos no fijos.

Por el contrario, en las Sentencias de la Sala de lo Social de 18 de septiembre de 2014 (recs. núms. 2320/2013 y 2323/2013, respectivamente) el Tribunal Supremo negó que el personal laboral de la sociedad mercantil AENA pudiera ser calificado como indefinido no fijo. En el mismo sentido, se pronunció en el caso de la empresa TRAGSA (STS de 6 de julio de 2016, rec. núm. 229/2015) y afirmó que «la construcción del indefinido no fijo es inaplicable a las sociedades anónimas, aunque pertenezcan al sector público, pues no están obligadas a cumplir con esos principios constitucionales del acceso "a la función pública”, que es a lo que se contrae el mandato del art. 103.3 CE». Posteriormente, han sido varios los autos inadmitiendo recursos de casación sobre esta materia invocando la doctrina establecida en las dos sentencias de 2014 en el caso $A E N A$, por ejemplo, en la empresa pública Canal de Isabel II (AATS de 24 de enero de 2019, rec. núm. 1843/2018, y de 2 de julio de 2019, rec. núm. 4135/2018).

Con estos últimos pronunciamientos parecía que la cuestión de la inaplicación de la figura del indefinido no fijo en las empresas públicas había sido zanjada por el Tribunal Supremo. Sin embargo, este último año ha vuelto a analizar este asunto en las Sentencias de la Sala de lo Social de 18 de junio de 2020 (recs. núms. 1911/2018 y 2811/2018) (ECLI:ES:TS:2020:2129 y ECLI:ES:TS:2020:2137), donde se ha pronunciado sobre las irregularidades en la contratación temporal de AENA. En estas dos sentencias, la Sala 4. ${ }^{a}$ ha concluido que la condición de trabajador indefinido no fijo es aplicable a las sociedades mercantiles públicas. Ello porque la figura del indefinido no fijo no se aplica exclusivamente a las Administraciones públicas ni a las entidades de Derecho público, sino que también opera en las entidades del sector público en las que el acceso se rige por los principios de igualdad, mérito y capacidad. En este sentido, las sociedades mercantiles públicas quedan fuera del ámbito de aplicación del Estatuto Básico del Empleado Público por su naturaleza jurídico-privada. Sin embargo, les es aplicable el art. 55 del mismo cuerpo legal, donde se establece la necesidad de que el acceso se ajuste a los principios de igualdad, mérito y capacidad, de conformidad con la DA 1.a.

Otra duda que despeja el Tribunal en estas sentencias es que el art. 103 de la Constitución únicamente hace referencia al «acceso a la función pública de acuerdo con los principios de mérito y capacidad». Por tanto, es aplicable en exclusiva al acceso a la condición de funcionario y no al acceso como personal laboral de la Administración. No 
obstante, según estima el Tribunal, el hecho de que la Carta Magna vincule al mérito y la capacidad con el acceso a la función pública no impide que una norma con rango de ley como es el Estatuto Básico del Empleado Público pueda exigir esos mismos principios al acceso al empleo público del personal laboral. Incluso, mediante su DA $1 .{ }^{\mathrm{a}}$ ampliar el ámbito de aplicación de los principios rectores de acceso al empleo público a las empresas pertenecientes al sector público que no son Administración pública.

\subsection{Reconocimiento judicial de derechos para el personal temporal e indefinido no fijo}

En el último año, no solo se han producido pronunciamientos relacionados con la finalización de la contratación temporal y si esta adolecía de irregularidades que producían la improcedencia del despido. El Tribunal Supremo también ha tenido que resolver cuestiones sobre los derechos del personal temporal y aquellos que han sido declarados indefinidos no fijos. La prohibición de trato diferente entre el personal con contrato temporal y el contratado fijo ha llevado a los tribunales a pronunciarse constantemente sobre cuestiones relacionadas con los derechos de estos primeros cuando la regulación o los acuerdos convencionales han recogido un tratamiento distinto que no estaba justificado. Conforme a ello, el Tribunal Supremo, en su Sentencia de la Sala de lo Social de 6 de marzo de 2019 (rec. núm. 8/2018), reconoció que los trabajadores con contratos temporales tienen derecho a acceder a la carrera profesional y, en consecuencia, a percibir el correspondiente complemento vinculado a ella en igualdad de condiciones que al personal fijo. Asimismo, en la Sentencia de la Sala de lo Social de 2 de abril de 2018 (rec. núm. 27/2017), el Tribunal Supremo reconoció el derecho a la promoción interna del personal indefinido no fijo.

En el año 2020, la Sala 4. ${ }^{\text {a }}$ del Tribunal Supremo se ha pronunciado sobre el reconocimiento de la excedencia voluntaria de los trabajadores interinos y sobre si tienen derecho a la segunda actividad el personal temporal e indefinido no fijo.

En la Sentencia de la Sala de lo Social de 17 de julio de 2020 (rec. núm. 1373/2018) (ECLI:ES:TS:2020:2945), el Tribunal Supremo resuelve recurso para la unificación de doctrina sobre el derecho de los trabajadores interinos a una excedencia voluntaria. En el caso concreto, una trabajadora había solicitado a su empleador, un ayuntamiento, una excedencia voluntaria por asuntos particulares en el puesto de socorrista que ocupaba como interina hasta la cobertura de la plaza en el proceso de selección o promoción. Se le denegó dicha excedencia por parte del ayuntamiento por ser incompatible con el contrato de interinidad. El Tribunal recuerda la doctrina del Tribunal de Justicia de la Unión Europea y la de la Sala $4 .^{a}$ con relación a la prestación de servicios temporales y derechos laborales, y reconoce el derecho de los trabajadores interinos a la excedencia voluntaria con derecho preferente al reingreso en la plaza vinculada al contrato, siempre que en ese momento del reingreso dicha plaza no se encuentre cubierta por otro trabajador.

Otra cuestión que se plantea es la forma de proceder si la plaza ha sido cubierta por otro trabajador interino. La Sala manifiesta que el empleador libremente puede 
suscribir otro contrato de interinidad para cubrir nuevamente la vacante o al sustituido. En este supuesto la excedencia del interino continuará, y si concluido el periodo de excedencia voluntaria la plaza sigue cubierta por el nuevo interino, el primero continuará manteniendo una expectativa de derecho de reingreso. En ningún caso, el nuevo interino "podrá ser cesado salvo que se incorpore el titular o sustituido, en cuyo caso no solo cesa ese interino sino el excedente, o si el tercero causa baja voluntaria en esa interinidad, en cuyo momento podrá el excedente interino ejercer ese derecho preferente de reingreso".

En relación con el derecho del personal temporal y los indefinidos no fijos a la segunda actividad, la Sala de lo Social del Tribunal Supremo reconoce el derecho a los bomberos forestales con contrato temporal o indefinido no fijo al acceso a segunda actividad en las mismas condiciones que el personal laboral fijo que trabaja en ese servicio, en la Sentencia de 3 de diciembre de 2020 (rec. núm. 87/2019) (ECLI:ES:TS:2020:4379).

La controversia litigiosa que se plantea en este recurso es si el personal temporal e indefinido no fijo que presta servicios como bombero forestal de la Xunta de Galicia tiene derecho a acceder a la segunda actividad al cumplir sesenta años de edad. El Tribunal Supremo determina que para resolver dicho recurso es necesario partir del principio de interpretación conforme, que obliga a aplicar el principio de no discriminación a los trabajadores con contrato temporal, contenido en el Acuerdo Marco sobre el trabajo de duración determinada.

La Sala de lo Social argumenta que el acceso a segunda actividad está indiscutiblemente comprendido en el concepto de condición de trabajo, a efectos del Acuerdo Marco, y que la Xunta de Galicia permite el paso a la segunda actividad a sus trabajadores fijos pero no de los trabajadores con contratos de duración determinada, lo que supone una desigualdad que no responde a razones objetivas que la justifiquen. Se trata de una cuestión que afecta a la prevención de riesgos laborales. La penosidad y peligrosidad de la extinción de incendios con más de sesenta años es la misma con independencia de si el contrato de trabajo es de duración indefinida o temporal, por lo que no debe excluirse el acceso a segunda actividad de los trabajadores temporales e indefinidos no fijos.

No obstante, el paso a segunda actividad no supone la desnaturalización de su relación laboral. Por tanto, los trabajadores temporales no pasan a ser trabajadores fijos de esa Administración, sino que su contrato se extinguirá por la reincorporación del titular o la cobertura reglamentaria de la plaza.

\section{Novedades jurisprudenciales en torno a la figura del funcionario interino}

Igual que ocurre con la contratación laboral temporal, la figura del funcionario interino no deja de ser objeto de resoluciones judiciales. Bien por las posibles irregularidades en su utilización, bien por la configuración de su régimen jurídico. 


\subsection{El cese de los funcionarios interinos}

El cese de los funcionarios interinos solo puede producirse por las causas legalmente previstas. En este sentido, el Tribunal Supremo, en su Sentencia de la Sala de lo Contencioso-Administrativo de 20 de enero de 2020 (rec. núm. 2677/2017) (ECLI:ES:TS:2020:75), ha establecido que no se encuentra entre las causas legalmente previstas para el cese de funcionario interino la incorporación de un funcionario de carrera distinto del titular del puesto ocupado por el interno. Este funcionario interino nombrado en sustitución de un funcionario de carrera con reserva de plaza solo debe producirse con ocasión de la ocupación efectiva de la plaza por el funcionario de carrera sustituido o por otro funcionario de carrera en el caso de que el titular inicial pierda el derecho a la reserva del puesto de trabajo y se realice una convocatoria al efecto.

\subsection{El abuso en el nombramiento sucesivo de interinos ante el Tribunal de Justicia de la Unión Europea}

Del mismo modo que ocurre con la contratación laboral temporal, también puede existir abuso en el nombramiento de funcionarios interinos $\mathrm{u}$ otras figuras similares reguladas por el Derecho público. Con relación a ello, ha sido importante la Sentencia del Tribunal de Justicia de la Unión Europea de 19 de marzo de 2020 (asuntos acumulados C-103/18 y 429/18) (ECLI:EU:C:2020:219). En esta ocasión el Tribunal de Justicia de la Unión Europea se pronuncia sobre la situación de temporalidad prolongada por el personal estatutario del Servicio de Salud de la Comunidad de Madrid. Los Juzgados de lo Contencioso-Administrativo núms. 8 y 14 plantearon cuestiones prejudiciales ante el Tribunal de Justicia de la Unión Europea sobre la interpretación de la cláusula 5 del Acuerdo Marco sobre el Trabajo de Duración Determinada, celebrado el 18 de marzo de 1999, que figura en el anexo de la Directiva 1999/70, en relación con el carácter abusivo de la temporalidad. En el litigio principal los recurrentes solicitaban el reconocimiento de personal estatutario fijo o, con carácter subsidiario, la condición de empleados públicos con un estatuto comparable al del personal fijo.

El Tribunal de Justicia de la Unión Europea determina el abuso en la prolongación indebida de la relación de interinidad de este personal y que esta es contraria al contenido de la cláusula 5 del Acuerdo Marco sobre las medidas destinadas a evitar la utilización abusiva de contratos o relaciones laborales de duración determinada. En este sentido, el Tribunal de Justicia de la Unión Europea pone de manifiesto que esta práctica de contratación es irregular y contraria a la directiva, aunque el empleador sea público y la renovación de la relación responda a las causas de nombramiento previstas en la normativa nacional. No es posible excluir del concepto de «relaciones laborales de duración determinada sucesiva» la situación de un empleado público que ocupa de modo permanente, en virtud de varios nombramientos, un puesto de carácter interino 
a falta de un proceso selectivo. Sin embargo, es el órgano jurisdiccional nacional quien debe determinar las consecuencias jurídicas de esta irregularidad conforme a su Derecho nacional aplicable.

No obstante, el Tribunal ofrece algunas orientaciones sobre las medidas adecuadas y procedentes para penalizar a la Administración con el objetivo de evitar estos abusos y compensar al personal afectado. No considera acertado para frenar los abusos convocar y organizar procesos selectivos que tienen por objeto cubrir de manera definitiva las plazas ocupadas provisionalmente aunque estén definidos en la normativa nacional unos plazos concretos de convocatoria. Ello porque no se garantiza que esos procesos se organicen efectivamente. Igualmente, el Tribunal rechaza que sea suficiente para acabar con los abusos lo dispuesto en la DT 4. ${ }^{a}$ del Estatuto Básico del Empleado Público sobre los procesos de consolidación de personal temporal. Esta disposición únicamente atribuye esa facultad a la Administración, pero de modo alguno está obligada a aplicar su contenido. Tampoco es partidario de extender la figura del indefinido no fijo a estas situaciones porque la medida no permite alcanzar la finalidad perseguida por la cláusula 5 del Acuerdo Marco. La utilización de esta figura no equivale a que el personal afectado disfrute de las mismas condiciones de trabajo que el personal estatutario fijo y no sirve como sanción a la Administración.

Sin embargo, el Tribunal considera que una medida adecuada para sancionar los abusos puede ser la indemnización. Pero es necesario que esta indemnización no solo sea proporcionada, sino también lo bastante efectiva y disuadiría como para garantizar la plena eficacia de dicha cláusula. En este sentido, deben ser los juzgados nacionales los que determinen si la indemnización equivalente a la abonada en caso de despido improcedente es la medida adecuada para prevenir y sancionar el abuso.

El Tribunal Supremo tuvo oportunidad de pronunciarse acerca de estas cuestiones en sus Sentencias de 26 de septiembre de 2018 (rec. núm. 785/2017) con respecto al personal estatutario y (rec. núm. 1305/2017) en relación con el cese de un funcionario interino. En esta ocasión el Tribunal declaró nulo el cese del funcionario interino al considerar abusiva la utilización de contratos de duración determinada. A su vez, reconoció se derecho a mantenerse en su puesto, percibiendo las retribuciones no abonadas, mientras la Administración no cumpliera con la normativa vigente. Ello porque el funcionario interino cubría necesidades que no tenían carácter provisional, sino permanente y estable. No obstante, la Sala de lo Contencioso-Administrativo consideró que en estos supuestos no es subsumible la doctrina de la Sala de lo Social de convertir la relación de funcionario interino en personal indefinido no fijo. En palabras del Tribunal, «la solución jurídica aplicable no es la conversión del personal que fue nombrado como funcionario interino de un ayuntamiento, en personal indefinido no fijo, aplicando de forma analógica la jurisprudencia del orden social, sino, más bien, la subsistencia y continuación de tal relación de empleo, con todos los derechos profesionales y económicos inherentes a ella, hasta que la Administración cumpla en debida forma lo que ordena la norma de carácter básico». 
El Tribunal en estos casos rechazó el derecho a una indemnización, ya que esta se produciría cuando tuviera lugar el cese definitivo y habrá que atender a las circunstancias singulares de cada caso.

En la Sentencia de la Sala de lo Contencioso-Administrativo de 23 de noviembre de 2020 (rec. núm. 5347/2018) (ECLI:ES:TS:2020:3861), el Tribunal Supremo ha considerado que el cese de un funcionario interino, con una relación prolongada en el tiempo, en este caso de más de siete años, no determina derecho a indemnización, pues en este caso no concurría un supuesto de sucesivos contratos, sino se trataba de una única vinculación funcionarial.

\subsection{Reconocimiento judicial de condiciones de trabajo al personal interino}

$\mathrm{Al}$ igual que ocurre con el personal contratado temporal o el personal indefinido no fijo, la Sala 3. ${ }^{\text {a }}$ del Tribunal Supremo se ha pronunciado sobre los derechos de los funcionarios interinos y, especialmente sobre la no discriminación frente al estatuto jurídico de los funcionarios de carrera.

En la Sentencia de la Sala de lo Contencioso-Administrativo de 18 de febrero de 2020 (rec. núm. 4099/2017) (ECLI:ES:TS:2020:454), el Tribunal Supremo se pronuncia sobre el derecho de los funcionarios interinos a la carrera profesional. La Sala recuerda la jurisprudencia sentada sobre la materia, por la que admitió el derecho a la carrera profesional de los funcionarios interinos de larga duración, es decir, que su relación temporal sobrepasara los cinco años.

La doctrina establecida por el Tribunal Supremo tiene en cuenta los criterios de las resoluciones del Tribunal de Justicia de la Unión Europea en relación con la Directiva 1999/70/CE. En ellas el Tribunal de Justicia de la Unión Europea estableció que la participación en la carrera profesional y sus beneficios económicos están sujetos a las condiciones de trabajo (naturaleza del trabajo, condiciones laborales y formación) y como Derecho social de la Unión no puede ser interpretado restrictivamente. Por tanto, el Tribunal Supremo determinó que, si la única diferencia es la condición de temporalidad, para «el mantenimiento de la diferencia entre los funcionarios interinos de larga duración y los funcionarios de carrera es necesario que exista una razón objetiva basada en elementos precisos y concretos que caractericen a la condición de trabajo o responda a una necesidad de lograr los objetivos y fines de la Administración».

En este sentido, el Tribunal Supremo concluye que no existe ninguna causa objetiva para la diferenciación entre el personal interino y los funcionarios de carrera. El criterio de diferenciación es una norma nacional abstracta y general relativa a la naturaleza temporal de la relación de servicios, por lo que no se puede perpetuar la situación desfavorable de los interinos. Por tanto, «existe discriminación de este personal por condicionarse su participación en la carrera profesional diseñada en el acuerdo recurrido a la circunstancia de haber superado un proceso de ingreso, y, por tanto, a la adquisición precisa de 
la condición de funcionario de carrera o personal laboral fijo, ello por no admitirse que ese condicionamiento integre una causa objetiva que justifique la diferencia de trato».

Esta doctrina se ha reiterado en las Sentencias de la Sala de lo Contencioso-Administrativo de 17 de noviembre de 2020 (rec. núm. 4641/2018) (ECLI:ES:TS:2020:3743), donde se ha reconocido el derecho a la carrera profesional horizontal y al complemento de carrera a un funcionario interino, y de 28 de mayo de 2020 (rec. núm. 4753/2018) (ECLI:ES:TS:2020:1363), donde ha considerado que el tiempo de servicio como interina debía tenerse en cuenta para la progresión en la carrera profesional.

Igualmente, en la Sentencia de la Sala de lo Contencioso-Administrativo de 14 de octubre de 2020 (rec. núm. 6333/2018) (ECLI:ES:TS:2020:3184), el Tribunal Supremo ha afirmado que puede declararse a los funcionarios interinos en situación de servicios especiales en los mismos supuestos previstos para los funcionarios de carrera. Del mismo modo, afirma que, con carácter general, debe computarse el tiempo transcurrido en dicha situación como experiencia equivalente a las funciones de la categoría a la que se concurre.

\section{EL CONVENIO COLECTIVO COMO FUENTE REGULADORA DE LAS CONDICIONES DE TRABAJO DEL PERSONAL DE UN AYUNTAMIENTO}

\section{Convenio colectivo aplicable cuando el ayuntamiento carece de convenio colectivo propio}

Es frecuente que los ayuntamiento con un tamaño pequeño o, en algunos casos, de tamaño mediano carezcan de un convenio colectivo propio. Ello genera muchas controversias a la hora de determinar qué convenio colectivo se aplica a su personal. En el último año han sido varios los pronunciamientos del Tribunal Supremo en relación con esta cuestión.

La cuestión que resuelve el Tribunal Supremo en Sentencia de la Sala de lo Social de 3 de diciembre de 2020 (rec. núm. 408/2018) (ECLI:ES:TS:2020:4203) consiste en determinar cuál debe ser la fuente reguladora de las condiciones de trabajo, singularmente del salario, de un trabajador dedicado a las labores de construcción, contratado temporalmente por un ayuntamiento en el marco de un programa de empleo joven regulado por un decreto-ley de la Junta de Andalucía, que carece de convenio propio.

El trabajador solicitaba el abono de las diferencias salariales en aplicación del convenio colectivo para el sector de la construcción de la provincia de Granada, al considerar que había de regir las retribuciones contempladas en dicho convenio en la prestación de servicios para el ayuntamiento.

El Tribunal Supremo desestima el recurso de casación para la unificación de doctrina interpuesto por el trabajador ya que una Administración pública, que no tiene convenio 
colectivo u otro específicamente aplicable, no puede quedar afectada por lo dispuesto en un convenio sectorial del que no ha formado parte ni está representada por las asociaciones empresariales firmantes del mismo. Según la Sala, las Administraciones no pueden estar sujetas a normas convenidas por organizaciones patronales guiadas por intereses particulares o sectoriales que muy difícilmente podrán coincidir con los intereses públicos y generales de los ayuntamientos. Por tanto, las asociaciones empresariales carecen de la representatividad necesaria para extender los efectos de una negociación colectiva a tales entidades.

En el caso concreto, el Convenio General de la Construcción en su art. 4 establece que «la normativa de este convenio será de obligada y general observancia para todas las empresas, entidades públicas y trabajadores de las actividades enumeradas en el artículo anterior». De esta forma, el convenio en su ámbito personal comprende no a las empresas o entidades que se dedican principalmente a la construcción, sino que realicen dicha actividad de construcción, como es el caso habitual de las entidades locales, que ni han participado, ni han estado representadas en la negociación del convenio. Por tanto, según el Tribunal Supremo, «resultaría ilegal y contraria a las previsiones del art. 82 ET la extensión a las mismas de sus efectos». Los ayuntamientos no tienen como actividad principal o específica la de la construcción y, por tanto, no se encuentran comprendidos dentro del sector cuyo ámbito de aplicación delimita dicho convenio. Sin embargo, la Sala deja abierta la posibilidad de que dicho convenio colectivo pudiera ser eventualmente aplicable a otro tipo de entidades públicas dedicadas específicamente a la actividad de la construcción.

El Tribunal sostiene que si bien es cierto que la formalización de un convenio propio es la herramienta jurídica más adecuada para dar solución a la problemática de regular las relaciones laborales de los empleados que desarrollan diferentes actividades en un ayuntamiento, la ausencia de este podría ser solucionada por otros mecanismos previstos en el art. 92 ET, como son la adhesión a otro convenio o la extensión de otro convenio colectivo en vigor.

Sin embargo, la respuesta a la falta de un convenio colectivo propio de un ayuntamiento no puede ser la de aceptar la aplicación de diferentes convenios colectivos en razón a la actividad a la que están adscritos los empleados. Ello provocaría gravísimos efectos distorsionadores para el ente municipal y para sus propios trabajadores al suponer la gestión y aplicación no solo de distintos regímenes salariales, sino también de diferentes sistemas, entre otros, de jornada, categorías o vacaciones.

En esta situación y a falta de los mecanismos previstos en el art. 92 ET, el ordenamiento jurídico determina que ante la inexistencia de un convenio colectivo propio, las partes pueden pactar lo que tuvieran por conveniente dentro del respeto a la ley a los mínimos de derecho necesario [art. 3.1.c) ET]. Cuestión que ocurrió en el caso resuelto en la sentencia al pactar entre el ayuntamiento y el trabajador como salario el abono de la cantidad prevista como subvencionable por tal concepto en el plan de empleo, que resultaba sensiblemente superior a lo previsto para el salario mínimo interprofesional vigente. 
Esta misma doctrina ha sido aplicada en las Sentencias de la Sala de lo Social de 21 de mayo de 2020 (rec. núm. 1383/2018) (ECLI:ES:TS:2020:1548), de 9 de julio de 2020 (rec. núm. 4608/2018) (ECLI:ES:TS:2020:2638) y de 16 de julio de 2020 (rec. núm. 3865/2018) (ECLI:ES:TS:2020:2633).

\section{Convenio colectivo aplicable cuando el ayuntamiento contrata mediante programas de subvenciones}

Otra de las cuestiones que se han planteado en el último año relacionadas con los convenios colectivos aplicables al personal que presta servicios en un ayuntamiento es si en el supuesto de que se formalicen contratos laborales mediante programas que subvencionen dichos contratos, las retribuciones que deben abonarse al trabajador son las establecidas en la norma que determina la subvención o mediante las tablas salariales establecidas en el convenio colectivo propio del ayuntamiento.

Esta cuestión ha sido resuelta por el Tribunal Supremo en la Sentencia de la Sala de lo Social de 21 de mayo de 2020 (rec. núm. 1383/2018) (ECLI:ES:TS:2020:1548). La Sala $4 .{ }^{a}$ recuerda que el ayuntamiento empleador debe recurrir a alguna de las modalidades contractuales del Estatuto de los Trabajadores para formalizar su relación con el trabajador aunque la contratación se realice en el marco de una normativa que tenga por objeto promover la contratación. Ello determina que los derechos y obligaciones de las relaciones laborales sean los establecidos en el propio Estatuto, ya que la normativa reguladora de las subvenciones carece de competencia para regular las relaciones laborales. Por tanto, «la subvención, como su nombre indica, es solo una ayuda económica para el mantenimiento de la actividad y el fomento de empleo en este caso, pero no una excusa para incumplir la normativa laboral en materia de retribuciones».

Todo ello lleva al Tribunal a desestimar el recurso de casación para la unificación de doctrina interpuesto por el ayuntamiento, dado que las retribuciones que los trabajadores debieron percibir eran las contempladas en el convenio colectivo de la corporación local. Además, esta respuesta no se desvirtúa por el hecho de que los trabajadores no estén incluidos en la relación de puestos de trabajo (RPT) del ayuntamiento, ni tampoco el hecho de que el convenio colectivo no prevea la retribución de los contratos formalizados al amparo de la subvención. En este caso hay que atender a los servicios prestados por los trabajadores para determinar la correspondiente categoría profesional y, por tanto, la retribución a percibir.

Esta doctrina también ha sido recogida en las Sentencias de la Sala de lo Social de 22 de mayo de 2020 (rec. núm. 435/2018) (ECLI:ES:TS:2020:1496) y de 28 de octubre de 2020 (rec. núm. 3453/2018) (ECLI:ES:TS:2020:3822). 